\title{
PREDICTING CORONARY HEART DISEASE FROM MINOR SYMPTOMS AND ELECTROCARDIOGRAPHIC FINDINGS
}

\author{
GEOFFREY ROSE \\ Department of Epidemiology and Medical Statistics, \\ London School of Hygiene and Tropical Medicine, London W.C.1 \\ and \\ Epidemiology Department, \\ St. Mary's Hospital Medical School, London W.2
}

Many coronary heart disease (CHD) deaths and many attacks of myocardial infarction seem clinically to occur as unheralded catastrophes. This is surprising, considering that pathologically such events are preceded by years of progressive atherosclerosis and ischaemia. The present study estimates the frequency with which minor symptoms and electrocardiographic changes may occur in the years before these major 'unexpected' illnesses.

\section{RESULTS}

A group of 1,127 men, aged 35 to 59 and initially free of known CHD, have had annual examinations since 1961 (Rose, 1968), including a standard questionnaire on chest pain (Rose, 1962) and (on three occasions) an electrocardiogram. The ECGs were classified according to the Minnesota Code (Blackburn et al., 1960). Subjects were classified according to their symptoms as having or not having (a) a defined syndrome of 'angina of effort', and (b) a history of 'possible infarction' (defined as an attack of severe central chest pain lasting for half an hour or more). Experience in applying this questionnaire to population samples has shown that the ascertained cases tend to be less severe than the more familiar cases of angina and suspect infarction in ordinary clinical practice. Generally, in fact, these symptoms attracted little attention, and often the affected individuals had not even reported to their doctors.

During the first seven years of follow-up, 79 men developed major coronary illnesses ( 37 deaths, 34 cases of non-fatal myocardial infarction, and 8 cases of major angina only). In 29 of these men (37\%) the first major illness had been preceded by a positive questionnaire (i.e., angina or 'possible infarction' at any one or more of the interviews), and in $23(29 \%)$ by a 'positive' ECG (Minnesota code 1.1-2 or $4 \cdot 1-2$ or $5 \cdot 1-2$ or $7 \cdot 1)$. In 33 cases $(42 \%)$ the major illness occurred without any previous record of either kind of abnormality; $17 \%$ of these men had of reported 'non-specific' types of chest pain or discomfort, whilst others had failed to attend for their examinations. In fact major CHD illnesses occurred in only seven individuals who had attended two or more prior examinations, all completely negative. Only two such cases were in men with four or more prior examinations, all negative.

Predictive power may be expressed in variou ways: (1) the actual risk (incidence) in affected persons; (2) relative risk-the ratio of inciden rates in persons with and without the finding; (3) a finding may carry a high relative risk but still, ٌٌ if its prevalence is low, it may miss most of the $\propto$ subsequent cases. One therefore also wants to know the proportion of cases predicted.

Table I sets out these estimates of predictive power for major coronary illness in this study. In each of the classes the relative risk is about 3 and the seven-year incidence is around $20 \%$. The proportion ? of $\mathrm{CHD}$ cases predicted ranges from about $10 \%$ for

TABLE I

SEVEN AND A HALF.YEAR RISK OF CHD ACCORDING TO INITIAL EXAMINATION FINDINGS IN 1,127 MEN

\begin{tabular}{|c|c|c|c|c|}
\hline \multicolumn{2}{|c|}{ Initial Examination (1961) } & \multicolumn{3}{|c|}{ Follow-up (1961-8) } \\
\hline Positive Items & $\underset{\%}{\text { Prevalence }}$ & \begin{tabular}{|c|}
$\%$ \\
Developing \\
CHD
\end{tabular} & $\begin{array}{l}\text { Relative } \\
\text { Risk of } \\
\text { CHD }\end{array}$ & $\begin{array}{c}\% \text { of } \\
\text { Total CHD } \\
\text { Predicted }\end{array}$ \\
\hline $\begin{array}{l}\text { Symptoms } \\
\text { Angina } \\
\text { 'Possible infarction' } \\
\text { Angina or } \\
\text { 'possible infarction' }\end{array}$ & $\begin{array}{l}3 \cdot 6 \\
5 \cdot 3 \\
8 \cdot 0\end{array}$ & $\begin{array}{l}20 \\
22 \\
17\end{array}$ & $\begin{array}{l}3 \cdot 0 \\
3 \cdot 5 \\
2 \cdot 7\end{array}$ & $\begin{array}{l}10 \\
16 \\
19\end{array}$ \\
\hline $\begin{array}{l}\text { ECG } \\
\text { Major } \\
\text { Minor } \\
\text { Major or minor }\end{array}$ & $\begin{array}{r}3 \cdot 5 \\
6 \cdot 8 \\
10 \cdot 4\end{array}$ & $\begin{array}{l}17 \\
17 \\
18\end{array}$ & $\begin{array}{l}2 \cdot 7 \\
2 \cdot 7 \\
3 \cdot 1\end{array}$ & $\begin{array}{r}9 \\
16 \\
27\end{array}$ \\
\hline Symptoms or ECG & $16 \cdot 4$ & 16 & $3 \cdot 0$ & 37 \\
\hline
\end{tabular}


TABLE II

RISK OF CHD IN 1,127 MEN ACCORDING TO INITIAL EXAMINATION FINDINGS IN (a) FIRST THREE YEARS, AND (b) ENSUING FOUR AND A HALF YEARS

\begin{tabular}{|c|c|c|c|c|}
\hline \multirow[t]{2}{*}{ Items Positive in 1961} & \multicolumn{2}{|c|}{$\begin{array}{l}\text { Relative Risk } \\
\text { of CHD }\end{array}$} & \multicolumn{2}{|c|}{$\begin{array}{c}\text { Proportion } \\
\text { of Total } \\
\text { CHD Predicted } \\
\text { (as \% of cases in } \\
\text { period) }\end{array}$} \\
\hline & $1961-4$ & $1964-8$ & $1961-4$ & $1964-8$ \\
\hline $\begin{array}{l}\text { Symptoms } \\
\text { Angina } \\
\text { 'Possible infarction' }\end{array}$ & $\begin{array}{r}5.0 \\
10.0\end{array}$ & $\begin{array}{l}2 \cdot 1 \\
1.4\end{array}$ & $\begin{array}{l}16 \\
36\end{array}$ & $\begin{array}{l}7 \\
7\end{array}$ \\
\hline ECG 'positive' & $9 \cdot 3$ & $1 \cdot 5$ & 52 & 15 \\
\hline $\begin{array}{l}\text { Symptoms or } \\
\text { ECG 'positive' }\end{array}$ & 6.5 & $2 \cdot 0$ & 56 & 28 \\
\hline
\end{tabular}

angina and major ECG findings up to $37 \%$ for all abnormalities combined. Symptoms taken as a whole predicted a somewhat lower proportion of cases than ECG findings as a whole. Due to the large measure of independence between the two sets of findings, however, a combination was much more effective than either taken alone.

Table II shows predictive power in relation to length of follow-up. All the relative risks are much higher in the first three years, especially for 'possible infarction' and the ECG. Relative risks in the second period are low but still above unity.

\section{Discussion}

Similar evidence on the frequency of antecedent minor abnormalities has been reported from the Tecumseh study (Chiang et al., 1970). In our study these early manifestations of CHD were often transient. Of men classed at the initial examination as having angina, less than $50 \%$ remained positive a year later (Rose, 1968). Many who lost their symptoms also seemed to lose even the memory of them. Of men answering 'yes' to the question on severe central chest pain, about half when questioned a year later denied ever having had such a pain. Similarly, it is known that minor ECG findings are often evanescent (Ostrander, 1966).

This variability in the early manifestations of CHD implies that the probability of detecting changes before a major attack will depend on the number of times that the individual has been examined. With annual examinations, many cases that would otherwise have been called 'unexpected' were in fact foreshadowed.

The data presented in Table II suggest that these minor premonitory findings are powerful risk predictors only in the short and medium term. More needs to be known about the corresponding changes in predictive power over time for risk factors (such as blood pressure and blood cholesterol), which are not themselves manifestations of atherosclerotic disease: possibly the decline may be slower.

The ECG, like all methods of physical examination, has the limitation in mass population screening that it requires the actual presence of the subjects and the use of skilled staff. A symptom questionnaire has the potential advantage that it may be completed by the subjects themselves. In this study it was always administered by nurses. But when interviewer-administered and self-administered versions have been compared in random samples of the same population, we have found that the prevalence of positives is about twice as high with the selfadministered version. Nevertheless the experience of the U.S./U.K./Norwegian Migrants Study (Krueger, Rogot, Blackwelder, and Reid, 1970) shows that its predictive power is still both high and also relatively specific (Table III), suggesting that in the hurried conditions of a conventional interview or consultation one perhaps tends to miss a history of minor symptoms; but these may nevertheless be of serious prognostic import.

There is unfortunately no possibility of direct validation of the diagnostic reliability of measures of CHD, since there is no reference test which would identify with certainty all the false positive and false negative cases. The most that can be done is to study the association between the various available measures-in this case between certain early and probably non-specific manifestations, and the subsequent incidence of major clinical disease. The finding that $80 \%$ of symptom-positive and ECG-positive patients were alive and well seven years later does not mean necessarily that they were false positives: they may have been true positive cases but with a benign course. Equally, the occurrence of major disease in $20 \%$ of those who had been identified by questionnaire or ECG does not prove that these were true positives: they may have included false positives who subsequently happened to become ill.

Nevertheless, despite these uncertainties in inter-

TABLE III

PREDICTION BY POSTAL QUESTIONNAIRE IN THE U.S./ U.K./NORWEGIAN MIGRANTS STUDY: RELATIVE MORTALITY RISK IN A TWO-YEAR FOLLOW-UP OF SUBJECTS AGED UNDER 65 YEARS (KRUEGER et al., 1970)

\begin{tabular}{l|c|c|c|c}
\hline \multirow{2}{*}{ Symptom Group } & \multicolumn{3}{|c|}{ Relative Mortality Risk } \\
\cline { 2 - 4 } & \multicolumn{2}{|c|}{ CHD } & Other Causes \\
\cline { 2 - 4 } & Male & Female & Male & Female \\
\hline Angina & 4.8 & 6.3 & 1.6 & 1.8 \\
\hline & 3.0 & 6.8 & 1.1 & 1.0 \\
\hline
\end{tabular}


pretation of individual cases, it is valuable to have available these simple techniques of mass examination: they permit identification of a high-risk group of persons who stand in special need of preventive care. Experience in their application gives added support to the view that in most cases major CHD is potentially predictable (Chiang et al., 1970).

The data come from a prospective survey of bronchitis in London by Dr. C. M. Fletcher and Dr. C. M. Tinker. I am grateful to them for their cooperation, and to the nurses who conducted the examinations.

\section{REFERENCES}

Blackburn, H., Keys, A., Simonson, E., Rautaharju, P., and Punsar, S. (1960). The electrocardiogram in population studies: a classification system. Circulation, 21, 1160.
Chiang, B. N., Perlman, L. V., Fulton, M., Ostrander, L. D., and EpsteIn, F. H. (1970). Predisposing factors in sudden cardiac death in Tecumseh, Michigan. Circulation, 41, 31.

Krueger, D. E., Rogot, E., Black welder, W. C., and REID, D. D. (1970). The predictive value of a postal $\stackrel{9}{\rightarrow}$ questionnaire on cardio-respiratory symptoms. chron. Dis., 23, 411.

OSTRANDER, L. D. (1966). Serial electrocardiographic findings in a prospective epidemiological study. Circulation, 34, 1069.

Rose, G. A. (1962). The diagnosis of ischaemic heart $\vec{\circ}$ pain and intermittent claudication in field surveys. Bull. Wld Hlth Org., 27, 645.

(1968). Variability of angina. Some implications for epidemiology. Brit. J. prev. soc. Med., 22, 12. 